\title{
MÉTODO PEDAGÓGICO HISTÓRICO-CRÍTICO E O ENSINO DE CIÊNCIAS: CONSIDERAÇÕES PARA A DIDÁTICA E A PRÁTICA PEDAGÓGICA
}

\author{
Tiago Nicola Lavoura ${ }^{1}$
}

Este texto é fruto da minha participação no evento intitulado II Simpósio Materialismo Histórico-Dialético e Pesquisa em Ensino de Ciências e Educação Ambiental, promovido pelos grupos de pesquisa "Formação e Ação de Professores de Ciências e Educadores Ambientais" e "Educação Ambiental", vinculados ao Programa de Pós-graduação em Educação para Ciência da Faculdade de Ciências da UNESP - Universidade Estadual Paulista, campus Bauru-SP.

Na oportunidade dessa satisfatória participação, em minha intervenção, abordei a problemática do ensino de Ciências e o método pedagógico histórico-crítico, com ênfase na questão dos conhecidos "cinco passos" constitutivos do método, que possui a prática social como ponto de partida e de chegada do trabalho educativo, e seus momentos intermediários de problematização, instrumentalização e catarse (SAVIANI, 2009).

A intenção deste capítulo é apresentar, de forma sistematizada, alguns dos principais pressupostos e elementos teóricos do debate sobre o método na pedagogia histórico-crítica, considerando seus fundamentos edificados no materialismo histórico-dialético. Não obstante, num segundo momento do texto, pretendo desenvolver algumas considerações, ainda que sob a forma de notas preliminares, quanto à prática pedagógica histórico-crítica e o ensino de Ciências, abordando elementos imprescindíveis da organização e do desenvolvimento do fazer pedagógico, tomando como referência algumas contribuições presentes em Galvão, Lavoura e Martins (2019), no que tange à discussão dos fundamentos didáticos da pedagogia históricocrítica.

Importa esclarecer que se trata de notas preliminares sobre o ensino de Ciências e a prática pedagógica histórico-crítica por duas razões:

\footnotetext{
${ }^{1}$ Pós-doutor em Psicologia e Educação pela Universidade de Aveiro (UA), Portugal. Pós-doutor em Educação Escolar pela Universidade Estadual Paulista (UNESP), campus Araraquara. Doutor em Educação pela Universidade Federal de Minas Gerais (UFMG). Professor Titular da Universidade Estadual de Santa Cruz (UESC). Docente nos cursos de Graduação em Educação Física e do Programa de Pós-graduação em Educação Mestrado Profissional (PPGE-UESC). Coordenador do Grupo de Estudos e Pesquisas em Formação Humana e Educação Física (GEPEFEF-UESC). Contato eletrônico: nicolalavoura@gmail.com
} 
Primeiro, considerando minha formação acadêmica e profissional e a questão do objeto de ensino de Ciências. Evidentemente, não pertencer e nem ter formação na área de conhecimento, cuja discussão de desenrola impõe limites para qualquer intervenção.

Em segundo lugar, trata-se de uma aproximação preliminar, uma vez que há de se reconhecer todo o imenso campo aberto de possibilidades e desdobramentos de discussão, de desenvolvimento e avanço teórico-metodológico, e de consolidação da prática pedagógica histórico-crítica, que nossa própria teoria pedagógica ainda deve encarar e enfrentar, notadamente, no que se refere à questão de seus fundamentos didáticos e o ensino dos distintos objetos dos componentes curriculares da educação escolar, conforme suas especificidades e suas legalidades próprias, em que pese à importância de não se abandonar a necessidade de tal discussão ser realizada mediante o pressuposto de totalidade curricular (GALVÃO; LAVOURA; MARTINS, 2019), e isso inclui o objeto aqui pensado e debatido.

Dito isso, passemos imediatamente para a primeira parte deste texto, em que desenvolvo uma análise sistemática e rigorosa do método da pedagogia histórico-crítica para, em seguida, adentrar na discussão do ensino de Ciências e os fundamentos da didática desta teoria pedagógica, com vistas ao agir pedagógico histórico-crítico.

\section{Método Pedagógico Histórico-Crítico: A Problemática dos Cinco ‘Passos’ em Análise}

À luz dos próprios pressupostos do materialismo histórico-dialético, considera-se que toda teoria é edificada e desenvolvida para atender a determinadas necessidades da prática social efetivamente existente. Com efeito, toda formulação teórica é uma forma de atividade do ser humano pensante, que procura desenvolver e articular um sistema categorial ideal de juízos e conceitos com vistas a resolver os problemas da prática social, que historicamente a ele - ser humano - vão se impondo sob as mais diversas formas de determinações sociais.

Assim entendida, a teoria se revela como uma verdadeira reprodução ideal da própria realidade prática que necessita ser pensada em seu movimento histórico efetivo, como forma de significação real e fidedigna do mundo objetivo. O professor Dermeval Saviani assim explicita as relações entre teoria e prática:

A teoria depende, pois, radicalmente da prática. Os problemas de que ela trata são postos pela prática e ela só faz sentido enquanto é acionada pelo homem como tentativa de resolver os problemas postos pela prática. Cabe a ela esclarecer a prática, tornando-a coerente, consistente, consequente e eficaz. Portanto, a prática igualmente depende da teoria, já que sua consistência é determinada pela teoria. Assim, sem a teoria a prática resulta cega, tateante, 
perdendo sua característica específica de atividade humana. (SAVIANI, 2012, p. 108)

Tais postulados da relação teoria e prática que caracterizam as distintas atividades humanas, no decorrer do desenvolvimento histórico, nos são fundamentais para se pensar o trabalho educativo enquanto forma de ação e intervenção humana na prática social. Tal intervenção é portadora de certas finalidades e, necessariamente, exige daqueles que a realizam a capacidade de antever e antecipar idealmente aquilo que se pretende fazer na prática.

Decerto, as teorias pedagógicas constituíram-se, e constituem-se, ao longo da história da educação, a partir das necessidades de se pensar e produzir formulações teóricas para a prática educativa. Uma teoria pedagógica possui sua gênese, seu desenvolvimento, sua consolidação e, até mesmo, suas crises e condições de desaparecimento ou superação, a partir das particularidades históricas dinamizadas pelas contradições da prática social humana.

Não se pode negar que a atividade pedagógica, realizada por meio do trabalho educativo, se desenvolveu - como, em geral, ocorre com toda a prática humana - de forma espontânea, como uma atividade indiferenciada no interior da prática social global (SAVIANI, 2012). Não obstante, o desenvolvimento da humanidade como um todo e, no seu interior, o progressivo e complexo desenvolvimento da prática educativa, levou às exigências de concepções pedagógicas ou ideias pedagógicas, que nada mais são do que formulações ideais encarnadas e constitutivas da própria substância do desenvolvimento da prática educacional, expressando modelos formativos e projetos pedagógicos orientadores do agir educativo.

Saviani (2012) afirma que as concepções ou teorias pedagógicas emergiram no campo educacional com vistas a orientar e dirigir o modo de realizar o ato educativo. De forma geral, a constituição dessas teorias envolve três níveis de fundamentação ideal da prática educativa: o nível da filosofia da educação, o nível da teoria da educação e o nível da prática pedagógica.

O nível da filosofia da educação é aquele que, "sobre a base de uma reflexão radical, rigorosa e de conjunto sobre a problemática educativa, busca explicitar as finalidades, os valores que expressam uma visão geral de homem, mundo e sociedade" (SAVIANI, 2012, p. 142-143). Já o nível da teoria da educação compreende o conjunto dos elementos que correspondem ao lugar e ao papel da educação na sociedade, expressando as concepções e o entendimento de escola, educação e formação humana. Quando se trata de uma concepção 
identificada como uma verdadeira teoria pedagógica², esse nível da teoria da educação “[...] se empenha em sistematizar, também, os métodos, os processos e procedimentos, visando a dar intencionalidade ao ato educativo de modo que garanta a sua eficácia" (SAVIANI, 2012, p. 143). Por fim, o nível da prática pedagógica resulta na sistematização do modo como é organizado e realizado o ato educativo, considerando-se as especificidades da relação ensinoaprendizagem e professor-aluno.

Portanto, podemos entender as teorias pedagógicas, tomando de empréstimo a síntese de Saviani (2012, p. 143), como “[...] as diferentes maneiras pelas quais a educação é compreendida, teorizada e praticada", e a apropriação dessas formulações teórico-pedagógicas é de suma importância para todos aqueles envolvidos com o ato de ensinar nas diferentes áreas de conhecimento do currículo e nas distintas etapas do processo de escolarização, uma vez que elas - as teorias pedagógicas - incidem diretamente no fazer educativo.

Com efeito, teorizar sobre o trabalho educativo e a prática pedagógica é uma das formas de efetivação da práxis humana, uma vez que “[...] o ato de antecipar mentalmente o que será realizado significa exatamente que a prática humana é determinada pela teoria. Portanto, quanto mais sólida for a teoria que orienta a prática, tanto mais consistente e eficaz é a atividade prática" (SAVIANI, 2012, p. 109).

Dito isso, importa-nos compreender como se relacionam e se articulam os três níveis de fundamentação teórica aludidos anteriormente - filosofia da educação, teoria educacional e prática pedagógica - no âmbito da pedagogia histórico-crítica, uma vez que tal análise nos é imprescindível para a discussão do método pedagógico histórico-crítico. Preliminarmente, cumpre destacar que o peso de cada um desses níveis e a maneira como eles se combinam e se vinculam depende de cada uma das concepções pedagógicas existentes.

Por exemplo, Saviani (2012) explicita o caso da pedagogia nova, cujo nível da filosofia da educação está subsumido ao da teoria educacional, visto que a concepção humanista moderna subjacente ao nível da filosofia da educação dessa teoria pedagógica entende que o ser humano deve ser considerado e compreendido em sua existência empírico-fenomênica, como cada indivíduo um ser vivo que se diferencia dos demais na experiência real da vida cotidiana. Ao assim proceder, é a teoria educacional que deverá “dar conta das diferenças que caracterizam os indivíduos, os quais devem ser considerados nas suas situações de vida e na

\footnotetext{
${ }^{2}$ Importa lembrar aqui que, se toda pedagogia é uma teoria educacional, nem toda teoria educacional é uma pedagogia. Conferir Saviani (2009).
} 
interação com os outros indivíduos. A teoria da educação ganha, então, autonomia em relação à filosofia da educação" (SAVIANI, 2012, p. 68). Em decorrência disso, o nível da prática pedagógica é patenteado segundo tais princípios, valorizando a prática, as experiências, o cotidiano e os interesses dos alunos.

Nota-se que, no caso exemplificado, há uma sobreposição de um dos níveis em detrimento dos outros. Mas há, também, concepções pedagógicas em que um dos níveis de fundamentação não chega nem a ser desenvolvido, com uma absoluta carência de determinações em termos de formulação e desenvolvimento teórico. É o caso das teorias críticoreprodutivistas da educação, cujo nível da prática pedagógica inexiste, ou ainda, o caso da pedagogia tecnicista, cujo nível da filosofia da educação é tomado de empréstimo, de forma indireta e pela via dos pressupostos, da concepção analítica de educação - corrente filosófica que, enquanto tal, "não tem o objetivo de analisar e explicar o próprio fenômeno educativo e, muito menos, orientar a prática pedagógica” (SAVIANI, 2012, p. 68).

Ora, de modo muito diferente e distinto ocorre com a pedagogia histórico-crítica. Além de encontrarmos os três níveis de fundamentação com robusta presença nessa teoria pedagógica, aquilo que a diferencia das demais concepções pedagógicas tem a ver com a forma, por meio da qual se encontram vinculados e articulados esses níveis, "os quais estabelecem entre si relações recíprocas de modo que cada nível se comporta ao mesmo tempo como determinante e como determinado dos demais" (SAVIANI, 2012, p. 69).

Julgo que um dos problemas centrais relativos à tentativa pioneira de elaboração e desenvolvimento de uma didática para a pedagogia histórico-crítica (GASPARIN, 2012) se deu, precisamente, em virtude da desconsideração ou do não entendimento desse caráter diferenciado de articulação e determinação recíproca dos distintos níveis de formulação dessa teoria pedagógica. Por isso, ao nos atermos à discussão do método pedagógico histórico-crítica, sobretudo com a intenção de pensarmos possibilidades de organização e desenvolvimento da prática pedagógica histórico-crítica com o ensino de Ciências, há de se levar isso em conta.

O problema da transposição didática direta do método pedagógico histórico-crítico, na forma de elaboração de cinco passos a serem sequencialmente seguidos, na organização do trabalho didático, e executados em sala de aula sob a forma de indicação do que fazer na prática pedagógica decorre, a meu ver, de um equívoco fundamental, com a derivação de, pelo menos, três corolários problemáticos subsequentes.

O equívoco central se consubstancia na conversão do método pedagógico em procedimento de ensino, configurando-se naquilo que temos denominado de desmetodização 
do método da pedagogia histórico-crítica, com sua consequente didatização ou procedimentalização (GALVÃO; LAVOURA; MARTINS, 2019; LAVOURA; MARTINS, 2017).

Essa conversão - muitas vezes não intencional - de desmetodização do método, transformando-o em procedimentos de ensino, provoca não apenas o engessamento de todo o caráter de dialeticidade, processualidade, de movimento dinâmico, impulsionado por contradições, e de vinculações e determinações recíprocas entre os distintos níveis de formulação dos fundamentos teórico-metodológicos da pedagogia histórico-crítica, bem como, pode provocar a ruptura e uma indesejada autonomização, por exemplo, do nível da prática pedagógica para com os demais níveis da filosofia da educação e da teoria da educação, culminando numa didatização.

Nosso esforço tem sido envidado na direção de explicitar que o método pedagógico deve ser encarado como um fundamento lógico teórico-filosófico, que atravessa medularmente todos os níveis de fundamentação e formulação teórica da pedagogia histórico-crítica (os níveis da filosofia da educação, da teoria educacional e da prática pedagógica). O método pedagógico não pode ser pensado como um mero instrumento operacional para ser aplicado na imediaticidade da prática educativa, tendo em vista que, na esteira da tradição do materialismo histórico-dialético, o método corresponde ao movimento lógico-histórico que reflete o processo de desenvolvimento, mudança e transformação dos objetos e fenômenos da realidade objetiva, em diferentes graus de determinações, desnudando suas manifestações aparentes e imediatas da dimensão empírico-fenomênica do real e penetrando no desvelamento da dinâmica das relações das propriedades internas mais essenciais. (GALVÃO; LAVOURA; MARTINS, 2019)

Entendendo o trabalho educativo como uma atividade humana desenvolvida no interior da prática social global (SAVIANI, 2008a), nos parece coerente considerar o método pedagógico como conjunto articulado de fundamentos que expressa o movimento lógicohistórico de dinâmica, processualidade e contradições do desenvolvimento do trabalho educativo, penetrando nas relações internas e articulando organicamente os elementos mais determinantes da relação 'educação e sociedade' e dos processos de 'ensino e aprendizagem'.

Revelado aquele que entendemos ser o equívoco principal (e apresentada a possibilidade de sua superação), analisemos seus subsequentes problemas, dentre os quais visualizo três corolários essenciais. O primeiro deles se reflete no reducionismo de se associar, de maneira direta e imediata, o movimento do método de superação da síncrese à síntese pela mediação da 
análise a um esquemático postulado metodológico expresso na insígnia prática-teoria-prática ${ }^{3}$. Sob esse enfoque, o método pedagógico histórico-crítico partiria da prática, ascenderia à teoria, por meio da especificidade do trabalho educativo desenvolvido em sala de aula, e retornaria à prática.

Vale destacar que o próprio Saviani (2016) já explicitou que se trata de um equívoco esse postulado esquemático de tomar a prática-teoria-prática como um suposto método histórico-crítico. Conforme ele afirma:

[...] é uma leitura equivocada aquela que consideraria que a atividade educativa parte da prática social no sentido de que os educandos se encontram atuando na prática social e diante dos problemas enfrentados [...] eles saem da prática e iniciam a atividade educativa para realizar os estudos necessários para compreendê-la após o que, uma vez tendo uma nova compreensão, voltam à prática para desenvolvê-la com uma nova qualidade. (p. 94)

Um segundo corolário problemático é o explícito empobrecimento dos elementos que constituem os momentos determinantes do método pedagógico histórico-crítico. Esse empobrecimento é nítido quando observamos a associação da prática social inicial como sinônimo de 'leitura da realidade do aluno', na qual ele está inserido; problematização, como 'questões-problemas' levantadas; instrumentalização, como 'exposição de conteúdo'; catarse, como ‘avaliação' do que se aprendeu e; prática social final, como 'novas intenções e propostas de ação'.

Por outro lado, tal empobrecimento também é absolutamente compreensível e explicável, uma vez que a conversão do método pedagógico em procedimento de ensino faz com que aqueles elementos, que deveriam ser vistos como categorias lógicas ${ }^{4}$ do método pedagógico histórico-crítico, se convertam em ações procedimentais transformadas em um receituário do fazer pedagógico.

Conforme apontamos em Galvão, Lavoura e Martins (2019), prática social inicial, problematização, instrumentalização, catarse e prática social final são "categorias lógicas do método pedagógico que expressam diferentes graus de determinações das relações mais particulares entre ensino e aprendizagem e mais universais entre educação e sociedade" (p.

\footnotetext{
${ }^{3}$ Não por acaso, não são poucas às vezes em que se imputa a formulação ação-reflexão-ação, própria da pedagogia da formação do professor reflexivo, cuja referência metodológica ancora-se na epistemologia da prática, ao método da pedagogia histórico-crítica.

${ }^{4}$ Para uma apreensão rigorosa e consequente do entendimento do que sejam as categorias no materialismo histórico-dialético, sugiro a leitura de Cheptulin (1982), Kopnin (1978), Lênin (2018) e Marx (2011).
} 
142) (destaque dos autores). Portanto, tais categorias buscam articular todo o conjunto dos elementos mais determinantes da organização e do desenvolvimento do trabalho educativo com vistas a orientar o agir dos professores na educação escolar, não podendo ser transpostas na forma de procedimentos de ensino.

Por fim, o terceiro e último corolário problemático, decorrente da análise aqui realizada, diz respeito ao reluzente esquematismo de formalização dos já citados elementos do método pedagógico, numa lógica etapista de passos que devem ser seguidos uniformemente, expressos na sequência já conhecida de: 1. partir da prática social; 2. problematizar; 3. instrumentalizar; 4. realizar a catarse e; 5. retornar a prática social.

Em que pese a forte manifestação desse corolário, na prática pedagógica que se pretende histórico-crítica, penso que já se alertou suficientemente para o fato de que não se trata de passos que devam ser seguidos a partir de uma relação mecânica e ordenados em sequência cronológica (SAVIANI, 2009, 2012, 2016; SAVIANI; DUARTE, 2012). Conforme evidenciado, pelo próprio Saviani, no texto Escola e democracia II: para além da teoria da curvatura da vara (datado nos idos de 1982; portanto, estamos recuperando uma afirmação do autor de cerca de 40 anos atrás, e cuja formulação é clara e indubitável:

Em lugar de passos que se ordenam numa sequência cronológica, é mais apropriado falar aí de momentos articulados num mesmo movimento, único e orgânico. O peso e a duração de cada momento obviamente irão variar de acordo com as situações específicas em que se desenvolve a prática pedagógica. (SAVIANI, 2009, p. 67) (destaque meu)

As experiências que temos acumulado nos últimos anos por meio de pesquisas ${ }^{5}$, das situações de ensino na graduação e na pós-graduação, nas orientações de estágios curriculares supervisionados na educação básica e em programas de iniciação à docência, assim como, os frutíferos diálogos que temos estabelecido com secretarias municipais e estaduais de educação, têm demonstrado certa recorrência desse problema fundamental e seus corolários, no interior do campo da pedagogia histórico-crítica, considerando as práticas pedagógicas que reivindicam tal teoria como suporte e subsídio de fundamentação para o trabalho educativo.

Portanto, é preciso enfrentá-las com vistas à sua superação, para fazermos avançar a própria teoria pedagógica e o nosso agir educativo histórico-crítico no interior das escolas

\footnotetext{
${ }^{5}$ Cito, a título de ilustração, o trabalho que publicamos na Revista Histedbr, intitulado Rumo à outra didática histórico-crítica: superando imediatismos, logicismos formais e outros reducionismos do método dialético (MARSIGLIA; MARTINS; LAVOURA, 2019).
} 
públicas brasileiras. A seguir, apresento algumas considerações acerca da organização e do desenvolvimento da prática pedagógica que se quer histórico-crítica, buscando preliminares aproximações com o ensino de Ciências.

\section{A Prática Pedagógica Histórico-Crítica e o Ensino de Ciências}

Conforme explicitado por Saviani (2008a, 2009, 2011), a pedagogia histórico-crítica surge no quadro das concepções pedagógicas brasileiras como uma teoria da prática educativa alternativa aos limites colocados, por um lado, pela crise instituída no seio dos embates e dilemas existentes entre a pedagogia tradicional e a pedagogia nova e, de outro, pela falta de alternativa instaurada pelas teorias crítico-reprodutivistas da educação quanto ao problema do ensino escolar nos marcos da crítica da sociedade existente e da pedagogia tecnicista então hegemônica no último quarto da década de 1970.

As exigências da análise do problema educacional, que incorporassem as categorias de contradição e mediação, levarão Dermeval Saviani, assim, ao desenvolvimento de uma teoria pedagogia cuja primazia da lógica dialética se colocasse de forma explicitamente sistematizada, cunhando a expressão 'histórico-crítica' como sua denominação. Conforme ele aponta:

Em outros termos, o que eu quero traduzir com a expressão pedagogia histórico-crítica é o empenho em compreender a questão educacional com base no desenvolvimento histórico objetivo. Portanto, a concepção pressuposta nesta visão da pedagogia histórico-crítica é o materialismo histórico [dialético], ou seja, a compreensão da história a partir do desenvolvimento material da determinação das condições materiais da existência humana. No Brasil, esta corrente pedagógica firma-se, fundamentalmente, a partir de 1979. (SAVIANI, 2008a, p. 88) (destaque do autor)

É no âmbito desta perspectiva que se insere a pedagogia histórico-crítica: buscar compreender a questão educacional a partir dos condicionantes sociais, e ter como referência central a análise da realidade a partir de suas raízes históricas. Ora, me parece que há aqui uma profunda relação entre os fundamentos da pedagogia histórico-crítica e o ensino de Ciências. Vejamos:

Se um dos pontos de partida de formulação dessa teoria pedagógica anunciava a necessidade de superação da falta de enraizamento histórico das teorias educacionais críticoreprodutivistas, ou seja, a ausência da apreensão do movimento da história enquanto um sucessivo e complexo processo dialético de desenvolvimento impulsionado por contradições, urgia a questão da "passagem da visão crítico-mecanicista, crítico-a-histórica para uma visão 
crítico-dialética, portanto histórico-crítica" (SAVIANI, 2008a, p. 93). Nesse sentido, implicava colocar no centro da análise as raízes históricas e, sendo consequente com a concepção materialista histórico-dialética, Saviani recuperará com radicalidade o ser humano e as condições materiais de produção da existência humana, da vida social e da educação, uma vez que "Ser radical é agarrar as coisas pela raiz. Mas a raiz, para o homem, é o próprio homem" (MARX, 2010, p. 151).

Advém, pois, daí a compreensão de que "a natureza da educação passa pela compreensão da natureza humana" (SAVIANI, 2008a, p. 11), tratando-se de considerar a necessidade humana de produzir continuamente sua própria existência, num processo históricosocial de desenvolvimento, no qual o ser humano se distingue dos demais seres naturais - o que inclui os outros animais - e entra em contradição com a natureza - portanto, um ser natural que se destaca da natureza, e para agir sobre ela e transformá-la necessita negá-la, mas, dela se apropriar, ou seja, um verdadeiro processo de superação por incorporação.

Com isto em vista, pode-se dizer que estamos tratando de uma teoria pedagógica de base radicalmente histórica e historicizante e, portanto, encontramos, nessa acepção, uma profícua dimensão valorativa de ensino de Ciências à luz destes fundamentos. Há na pedagogia históricocrítica uma imperiosa relação entre o conhecimento objetivo sistematizado e a sua valoração em termos de formação da segunda natureza humana, ou seja, formação da humanidade em cada indivíduo singular.

O processo histórico-social imanente do ser humano de fazer-se humano por meio do trabalho e, a partir dessa atividade fundante do ser social, de todas as outras atividades humanas que concorrem na direção da humanização dos indivíduos, impõe-se uma dimensão valorativa do conhecimento que não pode ser suprimida. Decerto, transformar a realidade implica conhecê-la, ou seja, para que a práxis humana se realize é necessário captar a realidade em pensamento nas suas múltiplas determinações, conscientizando-se dela, descobrindo como se dá o funcionamento do mundo - natural e social.

O próprio ato de trabalho, desde o mais rudimentar até o mais avançado em termos tecnológicos e científicos, requer a descoberta das formas pela qual a natureza funciona, desvendando os mecanismos e as leis objetivas da realidade natural, para poder dela se apropriar e ela transformar. Vê-se, pois, que o conhecimento do mundo natural se constitui como fonte e instrumento de desvelamento do mundo real, concreto e objetivo, fundamentalmente necessário aos indivíduos que compõem o gênero humano, visto ser base e orientação da atividade humana de transformação da realidade natural. 
Quando nos questionamos para que ensinar Ciências na escola, a própria análise dos fundamentos da pedagogia histórico-crítica - fundamentos esses radicalmente necessários para a compreensão da natureza e especificidade da educação escolar - nos revela o elemento valorativo essencial relacionado à finalidade de se ensinar como o mundo natural funciona e como é possível aos seres humanos, a partir do conhecimento desse mundo natural, nele agir para transformá-lo.

Mais do que isso, o ensino de Ciências apresenta outro elemento valorativo que, na atualidade, torna-se um imperativo vital do nosso tempo: explicitar as consequências do processo de transformação da natureza para a humanidade. O que se produz, como se produz; as formas e os processos dessa produção e, consequente apropriação humana; a distribuição e socialização dos produtos e bens que são produzidos; os impactos e as consequências dessa produção na vida natural e na vida humana; dentre outras questões, emergem como um conjunto de problemas emblemáticos e tão representativos do trágico momento histórico que a humanidade atravessa, em que a dinâmica absolutamente expansionista, destrutiva e incontrolável do metabolismo (anti)social do sistema do capital subjuga tudo à lógica do seu processo de valorização, com terríveis e brutais consequências para a natureza e para os seres humanos (MÉSZÁROS, 2011).

Por fim, quanto mais se avança o processo histórico de transformação da natureza pelo ser humano, mais se atualiza a exigência de que se transmita às novas gerações o conhecimento objetivo da natureza e as possibilidades de transformação desta pela humanidade. O efetivo conhecimento, de como o agir humano pode fazer recuar as barreiras naturais e transformar cada vez mais o mundo natural em natureza social, interessa ao conjunto do gênero humano, o que implica considerar o contínuo movimento de entrelaçamento de conhecimentos gerados em distintos períodos da história humana. É uma conquista da humanidade todo o conhecimento sistematizado que se acumula e se condensa historicamente na forma de acervo e patrimônio cultural, e que precisa ser transmitido e socializado para as novas gerações.

Por isso, desde a educação infantil até o ensino médio, há uma radical valoração do ensino de Ciências na educação escolar, e essa valoração é muito cara à teoria pedagógica que compreende a socialização do saber sistematizado como forma de enfrentamento à contradição posta entre ser humano-natural e ser humano-cultural na educação infantil (GAMA, 2015), entre ser humano e sociedade no ensino fundamental, e entre ser humano e trabalho no ensino médio (SAVIANI, 2008b). Em todos os níveis de escolarização da educação escolar, portanto, o ensino de Ciências é 'interessado', vinculando-se a uma dimensão de valoração inextirpável. 
Aliás, visto que, na sociedade atual, a forma escolar de educação se erige como dominante, e constatada a importância dos conhecimentos sistematizados no processo de humanização, a pedagogia histórico-crítica tem se diferenciado das demais concepções pedagógicas hegemônicas existentes no campo da educação brasileira, no sentido de defender a especificidade da escola, valorizar a importância do trabalho educativo como elemento vital ao desenvolvimento cultural e humano, e contribuir para o processo de luta de edificação de uma sociedade substantivamente igualitária. Há ou não há uma explícita relação valorativa do conhecimento vinculado ao ensino de Ciências na educação escolar que é captado e considerado pela pedagogia histórico-crítica?

Constantemente se explicita que as finalidades educativas despontam como uma questão essencial para esta teoria pedagógica, visto que, para ela, são os fins a atingir que devem determinar os meios do processo formativo (SAVIANI, 2008a, 2009, 2012, 2016). Então, a dimensão valorativa do trabalho educativo com vistas à objetivação do devir, da processualidade do dever ser que é característico do processo formativo humano e da construção da realidade, não pode ser secundarizada, revelando-se importante a articulação entre o conhecimento e a valoração humana, com destacada atribuição ao ensino de Ciências na educação escolar.

Por outro lado, há de se considerar, também, que o ato educativo exige dos professores um efetivo trabalho de organização e sistematização pedagógica, de modo que o conhecimento sistematizado se converta em saber escolar, tornando-se assimilável pelos alunos nos tempos e espaços escolares. Conforme afirma Saviani (2008a, p. 18):

[...] para existir a escola não basta a existência do saber sistematizado. É necessário viabilizar as condições de sua transmissão e assimilação. Isso implica dosá-lo e sequenciá-lo de modo que a criança passe gradativamente do seu não-domínio ao seu domínio. Ora, o saber dosado e sequenciado para efeitos de sua transmissão-assimilação no espaço escolar, ao longo de um tempo determinado, é o que nós convencionamos chamar de "saber escolar".

Em decorrência dessa exigência, impõe-se aos trabalhadores em educação responsáveis, em última instância, pela realização da prática pedagógica, o pensar, antever e antecipar idealmente as máximas possibilidades de planejamento e sistematização do ato de ensinar em seu conjunto, o que envolve a consideração de uma série de elementos que configuram a tríade conteúdo-forma-destinatário (GALVÃO; LAVOURA; MARTINS, 2019; MARTINS, 2013), tríade essa que, em certa medida, é determinada pela dimensão valorativa - os fins a atingir - 
anteriormente postulada, e cujas propriedades internas se articulam com a didática históricocrítica e estão sintetizadas em seus fundamentos, tal como procuro expor na sequência.

Um dos polos dessa tríade remonta à dimensão do conteúdo, cabendo considerar a distinção entre aquilo que é o essencial e o acidental, o principal e o secundário, o fundamental e o acessório, no que diz respeito à seleção de conteúdos a serem ensinados às novas gerações com o intuito de promover a formação humana dos indivíduos (SAVIANI, 2008a). O trato com o conhecimento, à luz dos fundamentos do materialismo histórico-dialético, e os princípios histórico-críticos para a seleção de conteúdos de ensino (GAMA, 2015) são fundamentais, uma vez que eles determinam a noção de objetividade e o enfoque científico do conhecimento, a contemporaneidade do conteúdo de ensino e sua relevância social.

Quando pensamos na relação entre objeto do conhecimento e seleção de conteúdos de ensino, é imprescindível considerar o fundamento didático histórico-crítico que explicita que $a$ dimensão ontológica do trabalho educativo não pode ser desconsiderada (GALVÃO; LAVOURA; MARTINS, 2019). Isso significa que há uma profunda e real conexão entre trabalho educativo e vida natural e social, entre educação escolar e prática social, entre conhecimento e realidade objetiva, entre conteúdos de ensino e a dimensão ontológica do real, esta que estabelece necessariamente que aquilo que se expressa na educação escolar, no currículo, nos planejamentos de ensino e nos planos de aula, enquanto objetos de conhecimento e conteúdo de ensino, condensam uma dimensão viva, real, concreta, e que tais objetos e seus respectivos conteúdos possuem existência objetiva efetiva, independente da consciência dos sujeitos envolvidos na prática pedagógica.

Esse fundamento da didática histórico-crítica parece fazer ainda mais sentido quando pensamos no ensino de Ciências da natureza. Um dos desafios do ensino de Ciências é promover a reprodução ideal da realidade natural, isto é, o reflexo científico da natureza, buscando o máximo de objetividade, eliminando-se toda forma de subjetivismo, antropomorfismo ou misticismo.

$\mathrm{Na}$ esteira da tradição do materialismo histórico-dialético, a ciência deve refletir a realidade natural de forma desantropomorfizada (LUKÁCS, 1966), ou seja, assumindo o princípio de que os fenômenos naturais existentes na realidade objetiva independem dos seres humanos, da cultura ou da sociedade. Conforme explicita Duarte (2016), o fato de a natureza possuir uma dinâmica de funcionamento imanente é bastante emblemático, visto não existir teleologia na natureza. "Esse ato só surgiu com a atividade teleológica humana, ou seja, com o 
trabalho" (DUARTE, 2016, p. 75), a partir do ato de antecipar mentalmente aquilo que virá a se realizar na prática efetiva.

Vê-se, também, que o fundamento didático histórico-crítico que assume a exigência do pleno domínio do objeto do conhecimento a ser ensinado pelos professores aos alunos (GALVÃO; LAVOURA; MARTINS, 2019) adquire, então, importante evidência. A defesa intransigente da prioridade dos conteúdos no trabalho educativo como forma de se concretizar o "bom ensino", isto é, um ensino que reproduza os traços essenciais do objeto, requer que todas as situações didáticas do processo de ensino e aprendizagem sejam uma verdadeira fonte de saturação da riqueza das propriedades categoriais do objeto que se ensina (nesse caso, tratarse-á do objeto de ensino de Ciências).

Com efeito, a riqueza categorial do objeto só pode se expressar na forma de saber escolar por meio dos conteúdos de ensino. Conforme já afirmado, à luz do materialismo históricodialético, os objetos e fenômenos da realidade existem independentemente da consciência do sujeito e, como tal, o acervo de categorias que reflete tal objeto ou fenômeno corresponde a categorias ontológicas (MARX, 2011), constitutivas do objeto. Elas - as categorias - não são criadas pelo pensamento, mas sim, reproduzidas idealmente pelo sujeito que pensa o objeto. Conforme descreveu Cheptulin (1982, p. 98):

A subjetividade da consciência exprimi-se no fato de que ela existe como mundo interior, espiritual do homem-sujeito e da sociedade humana, que reflete o mundo exterior, a realidade objetiva. Mas, tudo o que constitui o mundo interior do sujeito, tudo o que entra na esfera da sua consciência, não depende dele. No mundo subjetivo do homem há aspectos e momentos que são condicionados pela realidade objetiva, que correspondem a ela e que não dependem nem do homem-sujeito, nem da humanidade. Esses aspectos e esses momentos representam igualmente o objetivo no subjetivo e constituem uma forma particular de existência do mundo exterior no mundo interior do sujeito. A consciência, sendo assim o reflexo subjetivo da realidade objetiva, representa a unidade do subjetivo e do objetivo.

Considerando ser o professor o sujeito que já domina o objeto do ensino em pensamento, ou seja, que já se apropriou do conjunto dos conhecimentos sistematizados, permitindo-o reproduzir o objeto em pensamento, cabe a ele viabilizar aos alunos - aqueles que ainda desconhecem o objeto, não dominam os conhecimentos e, portanto, ainda não se apropriaram do mesmo - as condições para que possam vir a reproduzir tal objeto em pensamento. A maneira de o professor assim proceder é por meio da identificação, seleção, dosagem e sequenciamento de conteúdos de ensino, extraindo os traços categoriais essenciais do objeto 
que se quer que os alunos venham a dominar, realizando o aludido processo de conversão do saber sistematizado em saber escolar ${ }^{6}$.

Decerto, desponta também o fundamento da didática histórico-crítica, cuja transmissão do conhecimento é concebida como núcleo essencial do método pedagógico (GALVÃO; LAVOURA; MARTINS, 2019). Esse fundamento possibilita conceber o método pedagógico não mais como uma referência mecânica que se estrutura rigidamente em passos sequenciais, mas, fundamento lógico-dialético cujas categorias centrais de prática social inicial, problematização, instrumentalização, catarse e prática social final estabelecem relações recíprocas de determinação, transitam e transformam-se uma nas outras e se concretizam, na prática pedagógica, conforme as situações específicas em que ocorre o processo didático. Por isso, a unidade concreta de sua materialização - do método - é o ato de transmissão, “[...] essência da conexão interna, fonte de todos os enlaces particulares de todas as partes constitutivas do método pedagógico em questão" (GALVÃO; LAVOURA; MARTINS, 2019, p. 143).

Outro polo da tríade diz respeito à dimensão das formas, a organização dos meios mais adequados por intermédio dos quais tornar-se-á possível a transmissão-assimilação dos conteúdos de ensino, o que implica considerar as formas lógico-metodológicas, os espaços, os tempos, as condições objetivas concretas, os materiais e instrumentos disponíveis, os procedimentos, dentre outros.

Considerando todos esses elementos essenciais destacados, o fundamento didático da pedagogia histórico-crítica que explicita ser sua prática pedagógica determinada por uma concepção ampliada de eixo e de dinâmica do ensino pautada na lógica dialética (GALVÃO; LAVOURA; MARTINS, 2019) se configura como um princípio medular da organização das formas - na sua articulação com o conteúdo e o destinatário.

Esse fundamento didático delimita não apenas a natureza do conhecimento a ser ensinado aos alunos - o que sugere sua articulação com o polo conteúdo, mas, notadamente, os

\footnotetext{
${ }^{6}$ É evidente que não se trata de considerar o conteúdo deslocado das formas. Na verdade, tal dicotomia é estranha à pedagogia histórico-crítica (além de outras falsas dicotomias, como saber popular e saber erudito, saber acabado e saber em processo), tendo em vista sua edificação segundo os princípios da lógica dialética. Saviani (2008a) aborda essa questão de maneira muito clara, quando está desenvolvendo a análise do processo de conversão do saber sistematizado em saber escolar. Diz ele: "Essa transformação é o processo por meio do qual se selecionam, do conjunto do saber sistematizado, os elementos relevantes para o crescimento intelectual do aluno e organizamse esses elementos numa forma, numa sequência tal que possibilite sua assimilação. Assim, a questão central da pedagogia é o problema das formas, dos processos, dos métodos; certamente, não considerados em si mesmos, pois as formas só fazem sentido quando viabilizam o domínio de determinados conteúdos.". (p.75) (destaque meu)
} 
princípios de organização das formas do conhecimento ao longo dos níveis de ensino da educação escolar, com uma respectiva propositura de trato metodológico.

Assim, pensar as formas de organização do conteúdo de ensino de Ciências ao longo do processo de vida escolar dos estudantes, sem perder de vista as características e especificidades de cada período de desenvolvimento dos indivíduos, implica num processo de sistematização dirigido à forma de viabilizar a assimilação do conhecimento, ou seja, as distintas formas por meio das quais se expressa a própria lógica de pensar dos alunos representativa dos distintos graus de apreensão do saber, dos distintos graus de generalização do pensamento, cujo processo de desenvolvimento se assenta no método de ascensão do abstrato ao concreto.

Dado que o eixo do ensino histórico-crítico remonta à lógica dialética de organização do saber, determinando tanto a amplitude quanto a qualidade do processo do conhecimento, é preciso que a forma de sistematização do saber escolar do ensino de Ciências tenha como referência os sucessivos graus de espiralidade do pensamento em sistemas de generalizações ascendentes com vistas ao concreto pensado, permitindo aos alunos, sucessivamente, a aquisição da capacidade de identificação dos dados da realidade, sistematização, ampliação e aprofundamento desses dados do real. (GALVÃO; LAVOURA; MARTINS, 2019)

Essa sucessiva capacidade lógica de tornar a realidade inteligível, decerto, não se institui naturalmente, exigindo um processo de ensino que esteja dirigido a essa finalidade. Portanto, é imprescindível considerar as formas de sua organização de modo que se viabilize as condições para o desenvolvimento da capacidade de apreensão da realidade em pensamento.

É uma tarefa imperiosa - e que deve ser realizada coletivamente, notadamente, conduzida pelos professores, estudiosos e pesquisadores da área - que se pense no ensino de Ciências, tendo como referência os denominados ciclos de escolarização ${ }^{7}$ do processo de organização e sistematização da lógica do conhecimento, uma vez que:

[...] os ciclos de escolarização, tomados como referência da prática de ensino histórico-crítica, permitem efetivar o ato de ensinar como processualidade, cujo ponto de partida é a representação caótica do objeto do conhecimento que, por meio de sucessivas análises e sínteses, vai extraindo suas "determinações mais simples" e descobrindo o conjunto de suas relações contraditórias e contínuas transformações, o que possibilita a concreção do

\footnotetext{
${ }^{7}$ Vale registrar que a pioneira e inaugural propositura das formas de organização e sistematização do conhecimento à luz da lógica dialética por meio dos ciclos de escolarização, tendo como fundamentos desta proposta o acervo à época disponível da pedagogia histórico-crítica e da psicologia histórico-cultural, foi de um Coletivo de Autores (1992) da área da Educação Física. Em Melo, Lavoura e Taffarel (2020), encontramos uma proposta de atualização dos referidos ciclos de escolarização.
} 
objeto no pensamento, tendo-o no ponto de chegada como "uma rica totalidade de determinações e relações diversas", ainda que seja o verdadeiro ponto de partida, tal qual afirmara Marx (2011). (GALVÃO; LAVOURA; MARTINS, 2019, p. 151)

Por sua vez, a dinâmica do ensino histórico-crítico se refere às formas de organização e sistematização do trabalho educativo, articulando o trato com o conhecimento (as formas lógico-metodológicas de seleção, organização e sistematização do conhecimento), a organização escolar (as condições de espaço tempo do processo de ensino) e a normatização escolar (o sistema de normas, de orientações e de planejamentos do ensino).

Precípua é, ao ensino de Ciências, a compreensão dos princípios metodológicos para o trato com o conhecimento e as suas respectivas formas lógicas de sistematização, considerandose o método de ascensão do abstrato ao concreto, as distintas dimensões entre a aparência e a essência dos fenômenos da realidade, a simultaneidade dos conteúdos enquanto dados dessa realidade, a provisoriedade e historicidade dos conhecimentos e dinâmica espiralada de ampliação da complexidade do conhecimento (GAMA, 2015).

Por último, o terceiro polo da tríade dirige-se ao destinatário, com o respectivo reconhecimento das possibilidades de desenvolvimento dos indivíduos (considerando tanto as características humanas efetivamente existentes, quanto as que podem vir a se configurar como neoformações) em cada momento concernente à periodização do desenvolvimento humano, bem como, cada etapa da vida escolar dos estudantes, com a devida adequação das formas e dos conteúdos de ensino às possibilidades sócio-cognoscitivas dos alunos, conforme a referida periodização (MARTINS, 2013).

Ademais, esse polo da tríade é importante por conferir destaque às distintas especificidades existentes entre, de um lado, o ensino e, de outro, a aprendizagem, mesmo que reconheçamos estar se tratando de dois elementos reciprocamente pertencentes a um único e indiviso processo da prática pedagógica. Por conseguinte, há que se ressaltar o fundamento da didática histórico-crítica que reconhece o ensino e a aprendizagem como percursos lógicometodológicos contraditórios e inversos (GALVÃO; LAVOURA; MARTINS, 2019).

A unidade contraditória que se estabelece entre ensino e aprendizagem é fundamental, uma vez que "[...] entre iguais ou quase iguais não se instalam contradições que movam o desenvolvimento" (MARTINS, 2013, p. 295). E, não por acaso, Saviani (2009) situa professor e aluno como agentes inseridos no interior da mesma prática social, entretanto, em posições distintas e diferenciadas no ponto de partida da prática educativa. Nesse momento inicial da 
ação educativa, há uma desigualdade real entre professor e aluno que, pela mediação da educação, objetiva-se torná-la numa igualdade possível. De acordo com ele:

O professor deve antever com uma certa clareza a diferença entre o ponto de partida e o ponto de chegada, sem o que não será possível organizar e implementar os procedimentos necessários para se transformar a possibilidade em realidade. [...] Não sendo preenchida essa exigência, cai-se no espontaneísmo. E a especificidade da ação educativa esboroa-se. (SAVIANI, 2009, p. 70)

A questão central é que o percurso lógico da aprendizagem é caracterizado pela apropriação do conhecimento e, enquanto tal, a ele corresponde o movimento que transita do empírico ao abstrato, do singular ao universal, do todo caótico e carente de determinações à generalização abstrata.

O aluno, sujeito da aprendizagem, precisa transitar do desconhecido ao conhecido, o que significa apoderar-se da matéria - ensino de Ciências - em seus pormenores, apropriar-se das complexas formas de desenvolvimento, das mais diversas conexões íntimas que há entre os vários elementos da totalidade de dado objeto de conhecimento - no caso, do mundo natural. Isso é condição para que ele possa superar a síncrese em direção à síntese, apreendendo em pensamento os distintos elementos da realidade natural nas suas múltiplas relações e determinações numerosas. Não obstante, a isso cumpre a mediação da análise, despontando o papel do professor e o percurso lógico do ensino que contraditoriamente se colocam como "mola propulsora" desse processo de desenvolvimento, uma vez que sozinho e abandonado a sua própria sorte, o máximo a que o aluno poderá alcançar são as denominadas abstrações elementares, estas que, segundo Kopnin (1978), não podem ser confundidas com as abstrações autênticas.

As primeiras, peculiarmente determinadas por uma generalização abstrata, típica da forma de pensamento que se edifica pelos conceitos empíricos, e cujo conteúdo é a própria dimensão fenomênica da realidade empírica apreendida como factualidade. Já as segundas, constitutivamente determinadas por generalizações essenciais, substanciam o pensamento que se desenvolve na forma de conceitos teóricos, tendo por conteúdo o processo de reprodução ideal do movimento do real, penetrando nas relações internas que desvelam a estrutura e a dinâmica, a gênese e o desenvolvimento da coisa-em-si (KOPNIN, 1978).

Portanto, para conseguir realizar esse caminho, o aluno depende de um guia, de um par mais desenvolvido que possa conduzi-lo a suplantar a ordem 'de baixo para cima' e auxiliá-lo a transcender os horizontes da cotidianidade. Alguém que já tenha superado a síncrese, que já 
tenha se apropriado do saber sistematizado e que domine o objeto do conhecimento. É o professor que, mediante a lógica do ensino, realiza o movimento de exposição da matéria, atendendo ao trajeto do geral ao particular, do abstrato ao concreto, à ordem 'de cima para baixo', atuando pedagogicamente a favor do desenvolvimento do aluno (GALVÃO; LAVOURA; MARTINS, 2019; MARTINS, 2013).

Compreende-se, pois, que a referida teoria pedagógica requalifica a própria dinâmica da natureza das indagações que muitas das vezes se fazem presentes na prática pedagógica (o que se ensina, como se ensina, a quem se ensina, para que se ensina), articulando dialeticamente e na forma de determinação recíproca a essência concreta da atividade educativa, sintetizando as intermediações entre conteúdo e forma e respectivos vínculos com o destinatário e as finalidades valorativas.

Assim encarado, o ato de ensinar assume uma concretude da ação pedagógica que assegura as referidas propriedades internas como unidade indissolúvel, impossibilitando que se tenha, por exemplo, o trato com os conteúdos disformes, a consideração das formas dissociadas dos conteúdos, ou ainda, o aluno empírico em detrimento do aluno concreto, cujas necessidades de desenvolvimento e formação desconsideram os condicionantes e as determinações históricosociais da realidade objetiva.

\section{Considerações Finais}

Em alusão aos elementos aqui desenvolvidos, verificamos que todo o movimento de construção e desenvolvimento teórico da pedagogia histórico-crítica é atravessado pela referência do materialismo histórico-dialético enquanto lógica e teoria do conhecimento da realidade concreta. O estofo teórico-metodológico e o arsenal categorial da lógica dialética materialista-histórica permitiram ao professor Dermeval Saviani a elaboração de uma concepção pedagógica que assumisse como vital a análise rigorosa, radical e de conjunto dos problemas educacionais brasileiros (SAVIANI, 1991).

O reconhecimento dessa assertiva é importante não só por destacar uma peculiaridade da pedagogia histórico-crítica, mas, fundamentalmente, para podermos visualizar as possibilidades didáticas e o desenvolvimento da prática pedagógica no ensino de Ciências, na medida em que não se pode descolar o agir educativo de seus fundamentos teóricos, estes que tanto subsidiam o pensar, o organizar e o fazer pedagógico na forma de unidade indivisível. 
Por demais conhecido que possa ser a delimitação do trabalho educativo históricocrítico como atividade humana que visa reproduzir, em cada indivíduo singular, de maneira direta e intencional, a humanidade que é produzida coletivamente pelo conjunto dos seres humanos $^{8}$ (SAVIANI, 2008a), é possível que nem sempre nossa atuação na educação escolar corresponda coerentemente com esse preceito.

Ao apresentar elementos de análise do método pedagógico e desenvolver alguns apontamentos preliminares sobre a prática pedagógica histórico-crítica e o ensino de Ciências, espero ter demonstrado o quão necessário é considerarmos o trabalho educativo como atividade cognoscitiva e teleológica, o que requer professores com sólida formação teórico-cultural e técnico-operacional, reconhecendo-se como intelectuais que devem atuar com rigorosidade, criticidade e cientificidade profissional no âmbito da educação escolar.

Considero que esses preceitos são caros a essa teoria pedagógica e, como tal, devem estar sempre no horizonte de todos aqueles que vislumbram a unidade entre o saber e o fazer, sobretudo, a realização de uma prática pedagógica histórico-crítica, coerentemente reconhecendo as intervinculações entre a dimensão valorativa, o conteúdo, as formas e o método, sem perder de vista o destinatário que se quer formar para que ele possa se colocar na condição de sujeito da história.

\section{Referências}

CHEPTULIN, A. A dialética materialista: categorias e leis da dialética. São Paulo: AlfaOmega, 1982.

COLETIVO DE AUTORES. Metodologia do ensino da educação física. São Paulo: Cortez, 1992.

DUARTE, N. Os conteúdos escolares e a ressurreição dos mortos: contribuição à teoria histórico-crítica do currículo. Campinas: Autores Associados, 2016.

GALVÃO, A. C.; LAVOURA, T. L.; MARTINS, L. M. Fundamentos da didática

histórico-crítica. Campinas: Autores Associados, 2019.

\footnotetext{
${ }^{8}$ Esta caracterização de trabalho educativo feita pela pedagogia histórico-crítica revela, em partes, o quão edificado ela está sob os fundamentos teórico-filosóficos do materialismo histórico-dialético, notadamente quando consideramos a concepção de ser humano no âmbito da teoria social marxiana (MARX, 2004; MARX; ENGELS, 2007) e marxista (CHEPTULIN, 1982; KOPNIN, 1978; MARKUS, 2015; SUCHODOLSKI, 1965; PINTO, 1979). Com efeito, a natureza social do ser humano e a defesa da centralidade da educação escolar no que diz respeito ao processo formativo por meio da apropriação e assimilação da cultura humana na forma dos conhecimentos sistematizados são características basilares desta nossa teoria pedagógica.
} 
GAMA, C. N. Princípios curriculares à luz da pedagogia histórico-crítica: as contribuições da obra de Dermeval Saviani. 2015. 233 f. Tese (Doutorado em Educação) Faculdade de Educação, Universidade Federal da Bahia, Salvador, 2015.

GASPARIN, J. L. Uma didática para a pedagogia histórico-crítica. 5. ed. rev. 2. reimpr. Campinas: Autores Associados, 2012.

KOPNIN, P. V. A dialética como lógica e teoria do conhecimento. Rio de Janeiro: Civilização Brasileira, 1978.

LAVOURA, T. N.; MARTINS, L. M. A dialética do ensino e da aprendizagem na atividade pedagógica histórico-crítica. Interface (Botucatu), Botucatu, v. 21, n. 62, p. 531-541, 2017.

LÊNIN, V. I. Cadernos filosóficos: Hegel. São Paulo: Boitempo, 2018.

LUKÁCS, G. Estética: la peculiaridad de lo estético. Cuestiones previas y de principio. Barcelona: Grijalbo, 1966. v. 1.

MÁRKUS, G. Marxismo e antropologia: o conceito de "essência humana" na filosofia de Marx. São Paulo: Expressão Popular, 2015.

MARSIGLIA, A. C. G.; MARTINS, L. M.; LAVOURA, T. N. Rumo à outra didática histórico-crítica: superando imediatismos, logicismos formais e outros reducionismos do método dialético. Revista Histedbr on-line, Campinas, v. 19, p. 1-28, 2019. Disponível em: https://periodicos.sbu.unicamp.br/ojs/index.php/histedbr/article/view/8653380. Acesso em: 19 nov. 2020.

MARTINS, L. M. O desenvolvimento do psiquismo e a educação escolar: contribuições à luz da psicologia histórico-cultural e da pedagogia histórico-crítica. Campinas: Autores Associados, 2013.

MARX, K. Manuscritos econômico-filosóficos. São Paulo: Boitempo, 2004.

MARX, K. Crítica da filosofia do direito de Hegel. 2. ed. rev. São Paulo: Boitempo, 2010.

MARX, K. Grundrisse: manuscritos econômicos de 1857-1858: esboço da crítica da economia política. São Paulo: Boitempo; Rio de Janeiro: EDUFRJ, 2011.

MARX, K.; ENGELS, F. A ideologia alemã: crítica da mais recente filosofia alemã em seus representantes Feuerbach, B. Bauer e Stirner, e do socialismo alemão em seus diferentes profetas (1845-1846). São Paulo: Boitempo, 2007.

MELO, F. D. A.; LAVOURA, T. N.; TAFFAREL, C. N. Z. Ciclos de escolarização e sistematização lógica do conhecimento no ensino crítico-superador da Educação Física: contribuições da teoria da atividade. Revista Humanidades e Inovação, Palmas, v. 7, n. 10, p. 117-134, 2020.

MÉSZÁROS, I. A crise estrutural do capital. 2. ed. rev. ampl. São Paulo: Boitempo, 2011.

PINTO, A. V. Ciência e existência: problemas filosóficos da pesquisa científica. 2. ed. Rio de Janeiro: Paz e Terra, 1979.

SAVIANI, D. Educação: do senso comum à consciência filosófica. 10. ed. Campinas: Autores Associados, 1991.

SAVIANI, D. Pedagogia histórico-crítica: primeiras aproximações. 10. ed. rev. Campinas: Autores Associados, 2008a. 
SAVIANI, D. Educação socialista, pedagogia histórico-crítica e os desafios de uma sociedade de classes. In: LOMBARDI, J. C.; SAVIANI, D. (org.) Marxismo e educação: debates contemporâneos. 2. ed. Campinas: Autores Associados, 2008b. p. 223-274.

SAVIANI, D. Escola e democracia. 41. ed. Campinas: Autores Associados, 2009.

SAVIANI, D. História das ideias pedagógicas no Brasil. 3. ed. rev. Campinas: Autores Associados, 2011.

SAVIANI, D. A Pedagogia no Brasil: história e teoria. 2. ed. Campinas: Autores Associados, 2012.

SAVIANI, D. O conceito dialético de mediação na pedagogia histórico-crítica em intermediação com a psicologia histórico-cultural. In: BARBOSA, M. V.; MILLER, S.; MELLO, S. A. (org.). Teoria histórico-cultural: questões fundamentais para a educação escolar. Marília: Oficina Universitária; São Paulo: Cultura Acadêmica, 2016. p. 77-102.

SAVIANI, D.; DUARTE, N. (org.). Pedagogia histórico-crítica e luta de classes na educação escolar. Campinas: Autores Associados, 2012.

SUCHODOLSKI, B. Teoria marxista de la educacion. México: Grijalbo, 1965. 